\title{
Erratum to: Optimization of Xylanase Production by Filamentous Fungi in Solid-State Fermentation and Scale-up to Horizontal Tube Bioreactor
}

\author{
N. Pérez-Rodríguez • F. Oliveira • B. Pérez-Bibbins • \\ I. Belo • A. Torrado Agrasar • J. M. Domínguez
}

Published online: 21 March 2015

(C) Springer Science+Business Media New York 2015

\section{Erratum to: Appl Biochem Biotechnol (2014) 173:803-825 \\ DOI 10.1007/s12010-014-0895-1}

The original version of this article unfortunately contained a mistake in the pictures depicted in the right column of Fig. 4 regarding the SEM photographs showing the morphology of lignocellulosic surface of a) raw corncob, b) destarched corncob, c) destarched corncob followed by $\mathrm{NaOH}$ treatment, d) destarched corncob followed by $\mathrm{NH}_{4} \mathrm{OH}$ treatment, e) destarched corncob treated by autoclave, and f) destarched corncob treated by autoclave and microwave.

The correct Figure should be the following:

The online version of the original article can be found at http://dx.doi.org/10.1007/s12010-014-0895-1.

N. Pérez-Rodríguez $\cdot$ F. Oliveira $\cdot$ B. Pérez-Bibbins $\cdot$ J. M. Domínguez

Department of Chemical Engineering, Faculty of Sciences, University of Vigo (Campus Ourense), As Lagoas s/n, 32004 Ourense, Spain

N. Pérez-Rodríguez $\cdot$ F. Oliveira $\cdot$ B. Pérez-Bibbins $\cdot J$. M. Domínguez $(\bowtie)$

Laboratory of Agro-food Biotechnology, CITI (University of Vigo)-Tecnópole, Parque Tecnológico de Galicia, San Cibrao das Viñas, Ourense, Spain

e-mail: jmanuel@uvigo.es

F. Oliveira $\cdot$ I. Belo

Centre of Biological Engineering, University of Minho, Campus de Gualtar, 4710-057 Braga, Portugal

A. T. Agrasar

Bromatology Group, Department of Analytical and Food Chemistry, Faculty of Sciences, University of Vigo (Campus Ourense), As Lagoas s/n, 32004 Ourense, Spain 


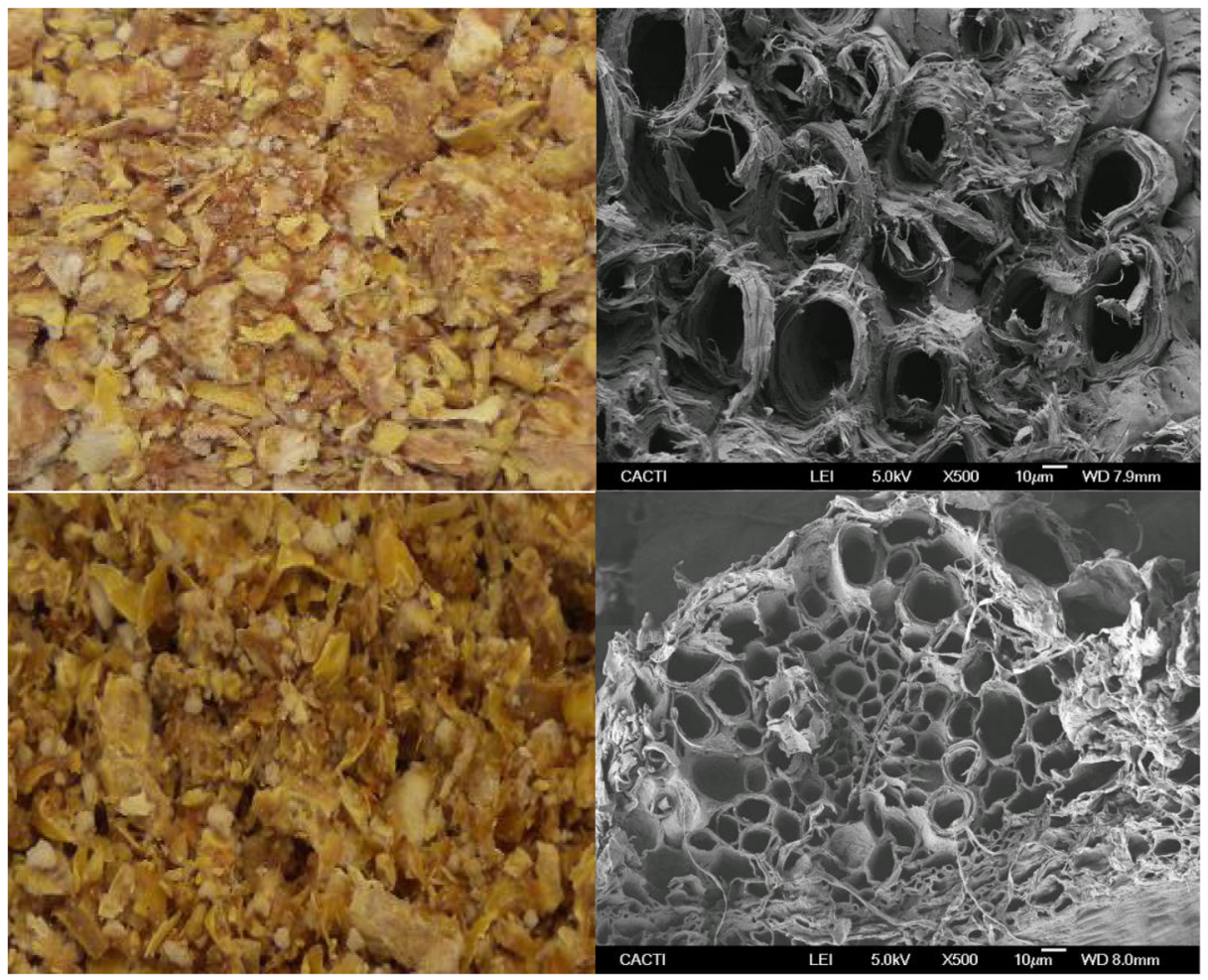

Fig. 4 Visual aspect and SEM photographs showing the morphology of lignocellulosic surface of a raw corncob, b destarched corncob, c destarched corncob followed by $\mathrm{NaOH}$ treatment, d destarched corncob followed by $\mathrm{NH}_{4} \mathrm{OH}$ treatment, e destarched corncob treated by autoclave, and $\mathbf{f}$ destarched corncob treated by autoclave and microwave 

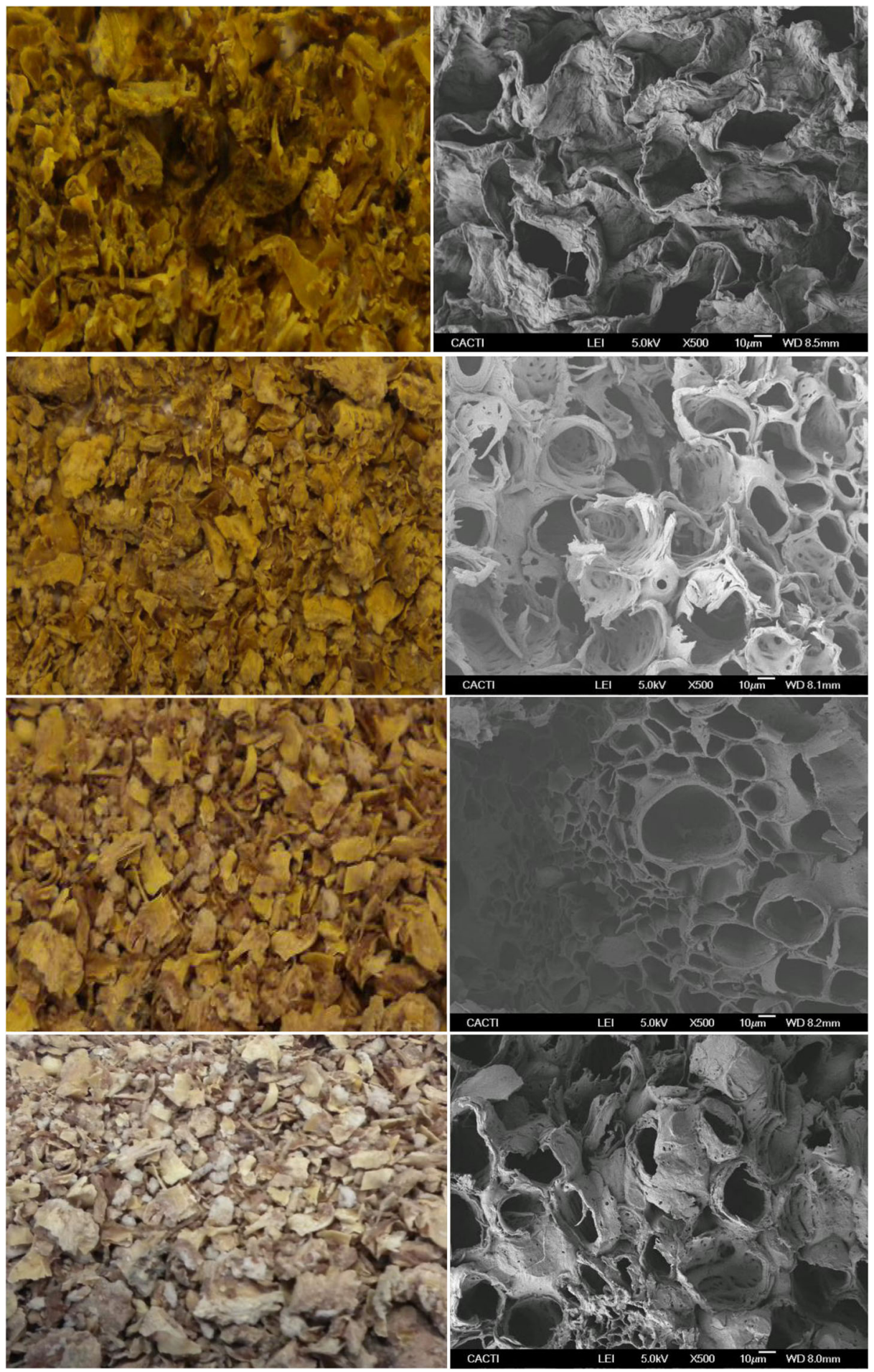

Fig. 4 (continued) 